\title{
Teaching Efficiency and Satisfaction of Clinical Practicum for College Students in Audiology Major
}

\author{
Jin-Dong Kim \\ Department of Speech and Hearing Therapy, College of Health Science, Catholic University of Pusan, Busan, Korea
}

\author{
Received: September 30, 2019 \\ Revised: November 6, 2019 \\ Accepted: November 27, 2019 \\ Correspondence: \\ Jin-Dong Kim, PhD \\ Department of Speech and \\ Hearing Therapy, \\ College of Health Science, \\ Catholic University of Pusan, \\ 57 Oryundae-ro, Geumjeong-gu, \\ Busan 46252, Korea \\ Tel: +82-51-510-0844 \\ Fax: $+82-51-510-0848$ \\ E-mail: jdkim@cup.ac.kr
}

\begin{abstract}
Purpose: This study investigated teaching efficiency and satisfaction with clinical practicum for college students in the audiology major. Through this research, the author seeks to improve quality and teaching methods in clinical practicum. Methods: Although a total of 140 participants who completed at least one course in audiology clinical practicum were recruited, the author analyzed only 131 surveys. The questionnaire consisted of general characteristics, audiology clinical practicum satisfaction, and teaching efficiency in audiology practicum education. All questions other than those related to general characteristics were prepared on the Likert 5-point scale. Results: Audiology clinical practicum satisfaction and teaching efficiency averaged 3.91 and 4.04, respectively. Audiology clinical practicum satisfaction and teaching efficiency based on participants' characteristics showed statistically significant differences related to clinical practicum period, health status, interpersonal relationships, difficult interpersonal relationships in clinical practicum, satisfaction with college life, satisfaction with major, and satisfaction with audiology clinical practicum. There were significant positive correlations between the sub-factors of teaching efficiency and audiology clinical practicum satisfaction. Conclusion: In the audiology major, teaching efficiency and clinical practicum satisfaction were very similar to or higher than those in health departments, and teaching efficiency was found to have a significant effect on clinical practicum satisfaction. Therefore, the College of Audiology and the Korean Faculty Council for Audiology will develop and investigate specific clinical practicum instructional plans and clinical practicum guidelines that can improve audiology clinical practicum satisfaction, and the introduction of a systematic system to reflect these results should be actively considered.
\end{abstract}

Key Words: Audiology, Satisfaction, Teaching efficiency, Clinical practicum.

\section{INTRODUCTION}

청능사(audiologist)는 청각학(audiology)을 기반으로 '청각 및 평형기관의 손상에 대한 평가와 신생아부터 노인까지 모든 연령층의 비의학적 청각관리를 담당하는 보건의료 전문가이다 (American Academy of Audiology, 2004). 우리나라의 청능사 양성 대학에서는 전문적 실무 능력을 갖춘 청능사를 양성하기 위하여 청각관리 분야의 국가직무능력표준(National Competency Standards, NCS)과 국제표준에 부합하는 청능사 관리. 운영 규정(2019년 개정)에 따라 이론 및 실습 과정을 운영하고 있다. 이 규정에서는 대학 정규 과정에서 학사학위를 취득하고 기초, 평가, 보청기, 재활 분야 각 6학점 이상, 실습 분야(평가실 습, 보청기실습, 재활실습) 9 학점 이상과 실습 시간 240시간 이

(c) This is an Open Access article distributed under the terms of the Creative Commons Attribution Non-Commercial License (https://creativecommons.org/licenses/by-nc/4.0) which permits unrestricted non-commercial use, distribution, and reproduction in any medium, provided the original work is properly cited.
상으로 총 36학점 이상을 취득하고 청능사자격증 시험에 합격 한 자에게 청능사 자격이 주어진다. 청능사 자격 검증 영역은 청각학 인정 교과목과 동일하게 NCS 청각관리 능력단위에 근 거하여 각 검정과목에 대한 지식(기초, 평가, 보청기, 재활)과 기 술(실습)을 이해하고 있는지 평가한다고 규정하고 있어 청각관 리 분야의 업무를 체계적으로 수행할 수 있도록 정비되어 있을 뿐 아니라 비의학적 청각관리를 담당하는 청능재활 전문가로 서 청능사의 역할과 전문성이 강조되고 있다. 그러나 특히 각 대학의 평가실습, 보청기실습, 재활실습 교과 과정에서 실습 시 간, 실습 내용에 대한 형식은 통일된 듯 보이지만 실습 장소와 실습 운영 방법, 실습 시수 산정 방법 등이 청능사 양성 대학마 다 다소 차이가 있다. 즉, 실습 장소가 교내 실습만으로 한정된 대학도 있고, 교내·외 실습 비율도 대학 간 차이가 크다. 또한 실습 시수 계산 및 방법에 관한 관리에 대해서도 지침이 제시 되지 않아 실습의 운영방식이 매우 다양하게 나타난다.

청능사의 청각관리 전문성과 난청인의 복지 증진을 위하여 
청능사 국가자격제도 도입이 꾸준히 논의되고 있는 현 시점에 서 청각학 교육의 질적 수준을 관리하고, 청각학 교육 여건을 국제적 수준으로 높이기 위한 학과 인증제 추진이 필요하다는 연구(Lee et al., 2017)가 이루어졌다. 청각학 전공 학생들은 청 각학 이론 교과목을 이수하여 청능사에게 필요한 전문적인 지 식을 습득하는 동시에 일정 시간의 실습 과정을 통해 청능사로 서의 실무 능력을 겸비할 수 있게 된다. 이러한 실습 교육은 이 미 습득된 이론적 지식을 실제 상황에 적용하여 대상자의 욕 구를 충족시키거나 문제 해결 능력을 기르고 배양하는 임상적 기술을 익히는 데 그 목적이 있다(Sung et al., 2007; Yu, 1997). 특히 임상실습은 대학과 실습 기관의 실습 지도자 간의 공동 계획과 지도 아래 실습 학생들이 일반 및 전문적인 분야에 실 제적 경험을 바탕으로 진행되므로 임상적 실무 능력을 익히기 위한 필수 교육 과정의 한 부분이라 할 수 있다. 청각학 전공 학 생의 실습은 청각 분야의 이론적 지식을 기반으로 임상 현장에 서 난청인의 평가, 재활, 상담 등에 관한 전문적인 청능사의 역 할을 실제 수행할 수 있도록 준비하는 교육 과정으로 청능사의 전문성 강화의 전제 조건이라고도 할 수 있는 청각학 실습의 질적 향상에 대한 필요성과 요구가 계속되고 있다. 청각학 실습 교육 과정은 교수, 학생, 학습내용이 필수 요소이므로(Kim \& Jung, 2006; Shin \& Kim, 1999), 청각학 실습 교과목의 개설 여부(학습 내용 포함), 실습 과정(실습 시간 및 학점) 및 교육 환 경(실습실 규모 및 기자재)과 더불어 교수진(또는 실습 지도자) 의 교수 효율성과 학생들의 실습 만족도는 실습 교육의 질적 제고를 위해 매우 중요하다. 따라서 체계적 청각실습 교육을 위 해서는 학생들의 실습 만족도, 실습을 지도하는 지도자의 교수 효율성, 실습 내용 및 실습 환경이 충실한지, 문제점은 없는지 를 확인하여 보완할 수 있는 근거를 마련해야 할 것이다.

청각학 실습 교육 과정에서 학생들은 학습자와 청능사의 역 할을 동시에 수행할 수 있어야 하므로 실습 이전에 실습생이 충 분히 역할을 인식하도록 교육해야 한다. 학생들이 경험하는 실 습에 대한 긍정적 경험, 심리적 부담감, 실습 스트레스 등은 실습 만족도와 전공 만족도와 높은 상관이 있으므로(Oh, 2013; Yoon \& Kim, 2013), 교내와 교외 실습에 따라서도 영향을 받을 수 있을 것이라 판단된다. 실습에서 실습 지도자의 역할은 학습자 의 학습 성과에 지대한 영향을 미친다는 연구를 보고하였다 (Kim \& Jung, 2006; Shin \& Kim, 1999; Sung et al., 2007). 청 각학 실습 담당 교수진의 실태에 관한 연구에서는 실습 지도자 의 인원 및 자격이 매우 다양하게 조사되었는데, 청각학 전공 학생들이 청능사로서의 적절한 임상실무 능력을 함양하기 위 해서는 청각학 전공 전임 교원이 직접 실습 교과목을 담당하는 방안이 가장 적절하다고 권고하고 있지만 비전임 교원이더라도 청각학 전공자로서 청능사 자격증을 취득하여 유지하고 있는
경우 실습 교과목을 담당할 수 있다고 하였다(Lee et al., 2017). 실습 교과 과정에서 학습 내용은 실습에서 다루는 교수 내용이며, 실습은 이러한 이론을 실제에 접목할 수 있는 교수 방법, 교내와 교외 실습 시간의 비율, 실습이 이루어지는 환경 등이 포함되어 그 내용과 형식이 방대하고 다양하다.

실습 교육에서 교수가 다양한 교수 활동을 통해 정해진 교육 목적을 달성한 정도를 파악하기 위하여 교수 효율성을 평가하 는 것은 매우 중요하다(Yu, 1997). 교수 효율성은 교육적 결과 에 대한 질적 특성으로 교수의 능력 수행의 효율성 정도를 파 악하여 교수 방법을 발전시킬 수 있다. Shin \& Kim(1999)은 교 수 방법, 교육 내용, 평가 과정의 공정성, 학생들에 대한 관심과 교과목에 대한 열의를 평가하는 것이 필요하다고 강조했다. 이 러한 교수 효율성은 실습 담당 교수가 학생들이 현장에서 전문 적 기술과 행동 방향을 잘 습득하도록 하는 것이며, 이는 임상 기관에 종사하기 위해 필요한 가치관과 태도를 잘 형성하도록 한다(Kim \& Jung, 2006). 청각학 전공 학생들이 실습과 청능 사로서의 역할을 잘 수행하기 위해서는 실습에 임하는 학생들 에게 전문적 지식뿐만 아니라 상호신뢰를 바탕으로 한 역할 모 델, 책임감 및 자신감을 주고, 전문적 지식을 임상에 접목시키 는 효율적인 교수법을 갖춘 실습 지도자의 역할이 중요하다.

임상실습이 필수적인 보건계열학과에서는 실습 만족도와 교 수 효율성에 대한 연구가 폭넓게 이루어졌다(Kim \& Jung, 2006; Kim \& Shin, 2015; Oh, 2013; Shin \& Kim, 1999; Sung et al., 2007). 청능사 국가자격증 도입 및 국제화 수준의 제고를 준비 하는 시점에서 청각학 전공 학생들의 실습 만족도와 교수 효율 성에 관한 연구는 실습 교과 과정을 더 나은 방향으로 변화시 키는 근거기반이 될 것이다.

따라서 본 연구에서는 우리나라에서 학부 청각학과를 운영 하는 대학의 청각학 전공 학생들을 대상으로 실습 만족도와 교 수 효율성을 파악하고, 연구 대상자 변인에 따라 실습 만족도 및 교수 효율성에 차이가 있는지와, 교수 효율성과 실습 만족도의 하위 요인 간의 관계를 살펴보고자 한다. 이를 통해 실습교육의 궁극적인 목표인 청각학 전공 학생의 임상수행 능력과 실습 교 육의 질적인 향상과 효율적인 지도 방법을 모색하는 근거자료를 제시함으로써 전문적인 청능사를 양성하는 데 기여하고자 한다.

\section{MATERIALS AND METHODS}

\section{연구 대상}

본 연구는 2019년 7월에서 8월까지 강원, 광주, 부산 · 경남 지 역에 소재한 대학의 청각 전공 재학생 중 청각실습 과목을 1 과 목 이상 이수한 학생 140명을 대상으로 청각학 실습 만족도와 교수 효율성에 관한 설문조사를 실시하였으나 일부 회수되지 
Table 1. General characteristics of the participants

\begin{tabular}{|c|c|c|}
\hline Characterization & Category & $\mathrm{n}(\%)$ \\
\hline \multirow[t]{2}{*}{ Gender } & Female & $93(71.0)$ \\
\hline & Male & $38(29.0)$ \\
\hline \multirow[t]{4}{*}{ Age } & $21-24$ & $94(71.8)$ \\
\hline & $25-30$ & $37(28.2)$ \\
\hline & $31-40$ & 0 \\
\hline & $\geq 41$ & 0 \\
\hline \multirow[t]{5}{*}{ Practicum period } & 1 semester & $3(2.3)$ \\
\hline & 2 semesters & $50(38.5)$ \\
\hline & 3 semesters & $14(10.8)$ \\
\hline & 4 semesters & $51(39.2)$ \\
\hline & 5 semesters & $12(9.2)$ \\
\hline \multirow{5}{*}{$\begin{array}{l}\text { Starting semester } \\
\text { of practicum }\end{array}$} & 2 nd grade 2 nd semester & $79(61.2)$ \\
\hline & 3rd grade 1st semester & $9(7.0)$ \\
\hline & 3 rd grade 2 nd semester & $41(31.8)$ \\
\hline & 4th grade 1 st semester & 0 \\
\hline & 4 th grade 2 nd semester & 0 \\
\hline \multirow[t]{4}{*}{ Practicum institution } & School labs & $100(37.3)$ \\
\hline & $\begin{array}{l}\text { General hospital } \\
\text { audiology clinic }\end{array}$ & $50(18.7)$ \\
\hline & $\begin{array}{l}\text { Personal hospital } \\
\text { audiology clinic }\end{array}$ & $49(18.3)$ \\
\hline & Personal hearing aid clinic & $69(25.7)$ \\
\hline \multirow[t]{5}{*}{ Practicum instructor } & Professors & $77(37.2)$ \\
\hline & Prof. of clinical practicum & $47(22.7)$ \\
\hline & Time lecturer & $13(6.3)$ \\
\hline & Field clinician & $69(33.3)$ \\
\hline & Etc & $1(0.5)$ \\
\hline \multirow[t]{5}{*}{ Health status } & Very good & $60(45.8)$ \\
\hline & Good & $38(29.0)$ \\
\hline & Average & $28(21.4)$ \\
\hline & $\mathrm{Bad}$ & $5(3.8)$ \\
\hline & Too bad & 0 \\
\hline \multirow[t]{5}{*}{ Academic performance } & Very good & $10(7.6)$ \\
\hline & Good & $27(20.6)$ \\
\hline & Average & $72(55.0)$ \\
\hline & Bad & $19(14.5)$ \\
\hline & Too Bad & $3(2.3)$ \\
\hline \multirow[t]{6}{*}{ Motivation of major select } & On the aptitude beaten & $40(30.5)$ \\
\hline & The high employment rate & $32(24.4)$ \\
\hline & $\begin{array}{l}\text { In consideration } \\
\text { of the achievement }\end{array}$ & $23(17.6)$ \\
\hline & By invitation others & $29(22.1)$ \\
\hline & For service & $3(2.3)$ \\
\hline & Etc & $4(3.1)$ \\
\hline \multirow[t]{5}{*}{ Interpersonal relationships } & Very good & $35(26.7)$ \\
\hline & Good & $59(45.0)$ \\
\hline & Average & $34(26.0)$ \\
\hline & Bad & $1(0.8)$ \\
\hline & Too bad & $2(1.5)$ \\
\hline
\end{tabular}

Table 1. General characteristics of the participants (continued)

\begin{tabular}{clc}
\hline \multicolumn{1}{c}{ Characterization } & \multicolumn{1}{c}{ Category } & $\mathrm{n}(\%)$ \\
\hline Difficult interpersonal & Prof. of clinical practicum & $18(14.5)$ \\
relationships in practicum & Practicum colleague & $13(10.5)$ \\
& Subjects & $20(16.2)$ \\
& Protector & $5(4.0)$ \\
& Practicum audiologist & $12(9.7)$ \\
& Administrative staff & $4(3.2)$ \\
& Etc & $52(41.9)$ \\
Satisfaction of college life & Very satisfaction & $21(16.0)$ \\
& Satisfaction & $52(39.7)$ \\
& Average & $50(38.2)$ \\
& Dissatisfaction & $7(5.3)$ \\
& Very dissatisfaction & $1(0.8)$ \\
Satisfaction of audiology & Very satisfaction & $25(19.2)$ \\
& Satisfaction & $63(48.5)$ \\
& Average & $39(30.0)$ \\
& Dissatisfaction & $3(2.3)$ \\
& Very dissatisfaction & 0 \\
patisfaction of audiology & Very satisfaction & $25(19.1)$ \\
& Satisfaction & $59(45.0)$ \\
& Average & $43(32.8)$ \\
& Dissatisfaction & $4(3.1)$ \\
& Very dissatisfaction & 0 \\
\hline \multirow{5}{*}{ practicum } & &
\end{tabular}

않은 설문지와 불성실한 응답을 제외하고, 총 131 명의 설문지를 최종 분석하였다. 연구 대상자의 기본 정보는 Table 1 과 같다.

\section{자료 수집 절차 및 설문지 구성}

청각실습 과목을 1 과목 이상 이수한 청각 전공 학생들에게 설문지를 직접 배포하고 연구의 취지 및 설문지 작성법을 설명 하였다. 설문에 대한 응답은 익명으로 처리되며, 연구 도중 언제 라도 철회할 수 있다는 것을 알려주고 서면 동의를 받은 후 편 의 표출하였다. 설문 응답은 실습 담당 교수나 실습 지도자가 개입되지 않은 상황에서 개별적으로 작성하도록 하였다. 설문지 는 총 140 부를 배부하였고, 그중 135 부가 회수되었으며, 불성실 한 응답 4 부를 제외하고, 총 131 부를 최종 분석 대상으로 하였 다. 설문지 응답에 소요된 시간은 약 10 15분 정도였다.

설문지 구성은 국가자격증 또는 민간공인자격증 응시 요건에 임상실습이 필수인 보건계열에서 전공 학생들의 실습 만족도 및 교수 효율성을 분석한 선행연구(Han \& Park, 2011; Kim \& Lee, 2014; Kim \& Shin, 2015; Oh, 2013; Yoon \& Kim, 2013) 를 참조하였다. 본 연구에 사용된 설문지의 내용 구성에 대한 내용 타당도 및 신뢰도는 선행연구에서 이미 검증된 바 있으나, 추가적으로 현재 대학에서 실습을 5 년 이상 지도한 교수 3 인에 게 감수를 받아 요인과 문항 내용을 수정·보완하였다. 설문지 는 총 75 문항으로 일반적 특성 15 문항, 청각실습 만족도 5 개의 
하위요인(청각실습 내용, 실습 지도자, 실습 환경, 실습 시간 및 평가, 실습 후 변화에 대하여 각 5 문항)에 대한 총 25 문항, 청각 실습 교육의 교수 효율성 5 개의 하위요인(교수 능력 관련 13 문 항, 인성적 자질 6문항, 역할 모델 6문항, 상호관계 5문항, 학생 참여 유도 관련 5문항)에 대한 총 35문항으로 구성하였다(Appendix). 모든 항목은 자기보고식 설문지에서 주로 사용하고 있는 Likert 5점 척도(매우 그렇다 5점 매우 그렇지 않다 1점) 로 하였다.

\section{자료 분석}

연구 대상자들의 일반적 특성과 청각실습 관련 현황 파악을 알아보기 위하여 빈도 분석을 사용하였고, 대상자 특성 간 청 각실습 만족도와 교수 효율성의 차이를 알아보기 위하여 독립 표본 $t$-검정(independent $t$-test) 또는 일원배치분산 분석(oneway analysis of variance)을 실시하였고, 청각실습 만족도 및 교수 효율성 하위요인 간 상관을 알아보기 위하여 Pearson 상 관 분석(Pearson correlation analysis)을 실시하였다. 모든 자 료는 SPSS 23.0 프로그램(IBM Corp., Armonk, NY, USA)을 사용하여 유의수준 0.01 혹은 0.001 미만에서 통계 처리하였다.

\section{RESULTS}

\section{청각실습 만족도}

청각실습 내용, 실습 지도자, 실습 환경, 실습 시간 및 평가, 실습 후 변화를 통하여 청각실습 만족도를 알아본 결과는 $\mathrm{Ta}-$ ble 2와 같다. Table 2에서 제시한 바와 같이 전반적 청각실습 만족도는 3.91이며, 하위 항목 중에서는 실습 후 변화에 대한 만족도(4.07)가 가장 높게 나타났고, 실습 내용에 대한 만족도 (3.80)가 가장 낮게 나타났다. 실습 내용의 5 개 하위 항목의 만 족도(평균 \pm 표준편차)는 각각 $3.98 \pm 0.70,4.11 \pm 0.66,4.02$ $\pm 0.76,3.42 \pm 0.89,3.52 \pm 0.86$ 으로 네 번째 항목과 다섯 번 째 항목이 유의하게 낮게 나타났다. 실습 지도자의 5 개 하위 항 목의 만족도(평균 \pm 표준편차)는 각각 $3.97 \pm 0.77,4.05 \pm$

Table 2. The results of average score and SD of five sub-items related to auditory clinical practicum satisfaction

\begin{tabular}{lcc}
\hline \multicolumn{1}{c}{ Characterization } & M & SD \\
\hline Practicum contents & 3.80 & 0.53 \\
Practicum instructor & 3.99 & 0.66 \\
Practicum environment & 3.84 & 0.76 \\
Practicum time and evaluation & 3.87 & 0.66 \\
The changing after practicum & 4.07 & 0.74 \\
The total satisfaction of audiology & 3.91 & 0.59 \\
clinical practicum & & \\
\hline
\end{tabular}

M: mean, SD: standard deviation
$0.72,4.03 \pm 0.73,3.92 \pm 0.81,4.02 \pm 0.76$ 으로 모든 항목에 서 유사하게 나타났다. 실습 환경의 5 개 하위 항목의 만족도(평 균 \pm 표준편차)는 각각 $3.59 \pm 1.04,3.85 \pm 0.91,3.90 \pm 0.83$, $4.08 \pm 0.75,3.79 \pm 0.89$ 로 첫 번째 항목이 유의하게 낮게 나타 났다. 실습 시간 및 평가의 5 개 하위 항목의 만족도(평균 \pm 표 준편차)는 $3.89 \pm 0.86,3.89 \pm 0.82,3.88 \pm 0.74,3.86 \pm 0.80$, $3.85 \pm 0.77$ 로 모든 항목에서 유사하게 나타났다. 마지막으로 실습 후 변화의 5 개 하위 항목의 만족도(평균 \pm 표준편차)는 각 각 $4.20 \pm 0.85,4.08 \pm 0.77,4.02 \pm 0.78,3.97 \pm 0.84,4.10 \pm$ 0.83 으로 모든 항목에서 유사하게 나타났다.

\section{교수 효율성}

교수 능력, 인성적 자질, 역할 모델, 상호관계, 학생 참여 유도 를 통하여 청각실습 교육의 교수 효율성을 알아본 결과는 $\mathrm{Ta}-$ ble 3과 같다. Table 3에서 제시한 바와 같이 전반적 교수 효율 성은 4.04이며, 하위 항목 중에서는 역할 모델(4.11)에 대한 교 수 효율성이 가장 높게 나타났고, 교수 능력(3.98)에 대한 교수 효율성이 가장 낮은 것으로 나타났다. 교수 능력의 13 개 하위 항목의 교수 효율성(평균 \pm 표준편차)은 각각 $3.90 \pm 0.82$, $3.98 \pm 0.72,4.02 \pm 0.73,4.04 \pm 0.74,4.01 \pm 0.74,4.03 \pm 0.76$, $3.98 \pm 0.85,3.90 \pm 0.87,3.98 \pm 0.83,3.98 \pm 0.81,4.05 \pm$ $0.77,4.05 \pm 0.83,3.86 \pm 0.87$ 로 나타났다. 인성적 자질의 6 개 하위 항목의 교수 효율성(평균 \pm 표준편차)은 각각 $4.01 \pm 0.87$, $4.08 \pm 0.80,4.01 \pm 0.82,4.07 \pm 0.84,4.04 \pm 0.84,3.99 \pm$ 0.87 로 나타났다. 역할 모델의 6개 하위 항목의 교수 효율성(평 균 \pm 표준편차)은 각각 $4.02 \pm 0.75,4.06 \pm 0.73,4.16 \pm 0.75$, $4.08 \pm 0.77,4.15 \pm 0.76,4.18 \pm 0.76$ 으로 나타났다. 상호관계 의 5 개 하위 항목의 교수 효율성(평균 \pm 표준편차)은 각각 $4.06 \pm 0.81,4.02 \pm 0.77,4.09 \pm 0.71,4.08 \pm 0.77,4.12 \pm$ 0.71 로 나타났다. 마지막으로 학생 참여 유도의 5 개 하위 항목 의 교수 효율성(평균 \pm 표준편차)은 각각 $4.06 \pm 0.77,3.98 \pm$ $0.82,4.05 \pm 0.75,4.05 \pm 0.76,4.01 \pm 0.78$ 로 나타났다. 즉 교 수 효율성 5 개 항목의 모든 하위 구성 내용은 서로 유사하게

Table 3. The results of average score and SD of five sub-items related to teaching effectiveness of preceptor

\begin{tabular}{lcc}
\hline \multicolumn{1}{c}{ Characterization } & $\mathrm{M}$ & $\mathrm{SD}$ \\
\hline Teaching ability & 3.98 & 0.68 \\
Personality qualities & 4.03 & 0.78 \\
Role models & 4.11 & 0.69 \\
Interrelationship & 4.07 & 0.69 \\
Students engage & 4.02 & 0.67 \\
The total teaching effectiveness of audiology & 4.04 & 0.66 \\
clinical practicum & & \\
\hline
\end{tabular}

M: mean, SD: standard deviation 
Table 4. The results of $t$-test or one-way analysis of variance for clinical practicum satisfaction in according with the characterization of subject

\begin{tabular}{|c|c|c|c|}
\hline Characterization & $\mathrm{M}$ & $\mathrm{SD}$ & $t$ or $\mathrm{F}$ \\
\hline \multicolumn{4}{|l|}{ Gender } \\
\hline Female & 3.84 & 0.56 & \multirow{2}{*}{$t=2.165$} \\
\hline Male & 4.08 & 0.61 & \\
\hline \multicolumn{4}{|l|}{ Age } \\
\hline $21-24$ & 3.80 & 0.57 & \multirow{2}{*}{$t=-3.41$} \\
\hline $25-30$ & 4.19 & 0.55 & \\
\hline \multicolumn{4}{|l|}{ Practicum period } \\
\hline 1 semester (a) & 3.93 & 0.86 & \multirow{5}{*}{$\begin{array}{c}\mathrm{F}=4.273^{*} \\
(\mathrm{~d}>\mathrm{b})\end{array}$} \\
\hline 2 semesters $(b)$ & 3.70 & 0.48 & \\
\hline 3 semesters $(\mathrm{c})$ & 3.73 & 0.52 & \\
\hline 4 semesters $(d)$ & 4.14 & 0.58 & \\
\hline 5 semesters $(e)$ & 4.05 & 0.73 & \\
\hline \multicolumn{4}{|l|}{ Starting semester of practicum } \\
\hline 2nd grade 2nd semester & 4.00 & 0.60 & \multirow{3}{*}{$\mathrm{F}=2.251$} \\
\hline 3rd grade 1st semester & 3.75 & 0.60 & \\
\hline 3 rd grade 2 nd semester & 3.78 & 0.53 & \\
\hline \multicolumn{4}{|l|}{ Health status } \\
\hline Very good (a) & 4.24 & 0.51 & \multirow{5}{*}{$\begin{array}{c}F=15.696^{\dagger} \\
(a>b, c)\end{array}$} \\
\hline Good (b) & 3.67 & 0.45 & \\
\hline Average (c) & 3.58 & 0.53 & \\
\hline $\operatorname{Bad}(\mathrm{d})$ & 3.59 & 0.61 & \\
\hline Too bad (e) & 3.91 & 0.58 & \\
\hline \multicolumn{4}{|l|}{ Academic performance } \\
\hline Very good & 4.37 & 0.57 & \multirow{5}{*}{$\mathrm{F}=2.687$} \\
\hline Good & 4.01 & 0.48 & \\
\hline Average & 3.85 & 0.60 & \\
\hline Bad & 3.84 & 0.49 & \\
\hline Too bad & 3.38 & 0.96 & \\
\hline \multicolumn{4}{|l|}{ Motivation of major select } \\
\hline On the aptitude beaten & 4.08 & 0.51 & \multirow{6}{*}{$\mathrm{F}=2.002$} \\
\hline The high employment rate & 3.97 & 0.60 & \\
\hline In consideration of the achievement & 3.76 & 0.66 & \\
\hline By invitation others & 3.78 & 0.59 & \\
\hline For service & 3.30 & 0.49 & \\
\hline Etc & 3.86 & 0.24 & \\
\hline \multicolumn{4}{|l|}{ Interpersonal relationships } \\
\hline Very good (a) & 4.19 & 0.60 & \multirow{5}{*}{$\begin{array}{r}\mathrm{F}=3.890^{*} \\
(\mathrm{a}>\mathrm{b}, \mathrm{c})\end{array}$} \\
\hline Good (b) & 3.88 & 0.58 & \\
\hline Average (c) & 3.70 & 0.46 & \\
\hline $\operatorname{Bad}(d)$ & 3.92 & 0.00 & \\
\hline Too Bad (e) & 3.34 & 0.93 & \\
\hline \multicolumn{4}{|c|}{ Difficult interpersonal relationships in practicum } \\
\hline Prof. of clinical practicum (a) & 3.52 & 0.38 & \multirow{5}{*}{$\begin{array}{c}F=3.849^{*} \\
(f>a)\end{array}$} \\
\hline Practicum colleague (b) & 4.02 & 0.43 & \\
\hline Subjects $(c)$ & 4.05 & 0.54 & \\
\hline Protector $(\mathrm{d})$ & 4.12 & 0.75 & \\
\hline Practicum audiologist (e) & 3.63 & 0.68 & \\
\hline
\end{tabular}

Table 4. The results of $t$-test or one-way analysis of variance for clinical practicum satisfaction in according with the characterization of subject (continued)

\begin{tabular}{lccc}
\hline \multicolumn{1}{c}{ Characterization } & M & SD & $t$ or F \\
\hline Administrative staff (f) & 4.81 & 0.10 & \\
Etc (g) & 3.95 & 0.57 & \\
Satisfaction of college life & & & \\
Very satisfaction (a) & 4.56 & 0.45 & \\
Satisfaction (b) & 4.00 & 0.37 & \\
Average (c) & 3.62 & 0.55 & $\mathrm{~F}=17.413^{\dagger}$ \\
Dissatisfaction (d) & 3.51 & 0.68 & $(\mathrm{a}>\mathrm{b}, \mathrm{c})$ \\
Very dissatisfaction (e) & 2.68 & 0.00 & \\
Satisfaction of audiology major & & & \\
Very satisfaction (a) & 4.56 & 0.47 & $\mathrm{~F}=26.826^{\dagger}$ \\
Satisfaction (b) & 3.89 & 0.37 & $(\mathrm{a}>\mathrm{b}, \mathrm{c}, \mathrm{d} /$ \\
Average (c) & 3.51 & 0.53 & $\mathrm{~b}>\mathrm{c})$ \\
Dissatisfaction (d) & 3.61 & 0.90 & \\
Very dissatisfaction (e) & 0.00 & 0.00 & \\
Satisfaction of audiology practicum & & & \\
Very satisfaction (a) & 4.65 & 0.34 & \\
Satisfaction (b) & 3.99 & 0.34 & $\mathrm{~F}=55.210^{\dagger}$ \\
Average (c) & 3.42 & 0.46 & $(\mathrm{a}>\mathrm{b}, \mathrm{c}, \mathrm{d} /$ \\
Dissatisfaction (d) & 3.42 & 0.55 & $\mathrm{~b}>\mathrm{c})$ \\
Very dissatisfaction (e) & 0.00 & 0.00 & \\
\hline
\end{tabular}

${ }^{*} p<0.01,{ }^{\dagger} p<0.001$. M: mean, SD: standard deviation

나타났다.

\section{대상자 특성에 따른 청각실습 만족도 비교}

청각실습 만족도가 대상자 특성에 따라 차이가 있는지를 알 아본 결과는 Table 4와 같다. Table 4에서 제시한 바와 같이 청 각실습을 4학기 동안 한 학생들이 2학기를 한 학생들보다 통계 적으로 유의하게 실습 만족도가 높은 것으로 나타났다 $(p<$ 0.01). 건강 상태가 매우 좋다고 생각하는 집단과 대인관계가 매 우 좋다고 생각하는 집단이 그렇지 않은 집단보다 실습 만족도 가 유의하게 높은 것으로 나타났다 $(p<0.01)$. 또한 실습 과정 에서 실습 담당 지도교수가 어려웠다고 생각한 집단이 실습 담 당 관련 직원이 어렵다고 생각하는 집단보다 실습 만족도가 유 의하게 낮았다 $(p<0.01)$. 대학생활과 청각 전공에 대해 매우 만 족하는 집단이 다른 모든 집단보다 통계적으로 유의하게 실습 만족도가 높았다 $(p<0.001)$. 그러나 연령, 성별, 실습 시작 학 기, 학업 성적, 전공 선택 동기에 따라서는 청각실습 만족도에 차이가 없었다.

\section{대상자 특성에 따른 교수 효율성 비교}

교수 효율성이 대상자 특성 간 차이가 있는지를 알아본 결과 는 Table 5 와 같다. Table 5 에서 제시한 바와 같이 청각실습을 4 학기 동안 한 학생들이 2학기를 한 학생들보다 통계적으로 유 
Table 5. The results of $t$-test or one-way analysis of variance for teaching effectiveness of preceptor in according with the characterization of subject

\begin{tabular}{|c|c|c|c|}
\hline Characterization & $\mathrm{M}$ & $\mathrm{SD}$ & $t$ or F \\
\hline \multicolumn{4}{|l|}{ Gender } \\
\hline Female & 4.00 & 0.64 & \multirow{2}{*}{$t=1.168$} \\
\hline Male & 4.15 & 0.68 & \\
\hline \multicolumn{4}{|l|}{ Age } \\
\hline $21-24$ & 3.95 & 0.66 & \multirow{2}{*}{$t=-2.51$} \\
\hline $25-30$ & 4.27 & 0.63 & \\
\hline \multicolumn{4}{|l|}{ Practicum period } \\
\hline 1 semester $(a)$ & 4.39 & 0.56 & \multirow{5}{*}{$\begin{array}{c}\mathrm{F}=3.538^{*} \\
(\mathrm{~d}>\mathrm{b})\end{array}$} \\
\hline 2 semesters (b) & 3.81 & 0.61 & \\
\hline 3 semesters $(c)$ & 3.97 & 0.67 & \\
\hline 4 semesters $(d)$ & 4.27 & 0.62 & \\
\hline 5 semesters $(e)$ & 4.07 & 0.75 & \\
\hline \multicolumn{4}{|l|}{ Starting semester of practicum } \\
\hline 2nd grade 2 nd semester & 4.11 & 0.65 & \multirow{3}{*}{$\mathrm{F}=2.274$} \\
\hline 3rd grade 1 st semester & 4.22 & 0.64 & \\
\hline 3 rd grade 2 nd semester & 3.87 & 0.64 & \\
\hline \multicolumn{4}{|l|}{ Health status } \\
\hline Very good (a) & 4.40 & 0.56 & \multirow{5}{*}{$\begin{array}{c}\mathrm{F}=14.993 \\
(\mathrm{a}>\mathrm{b}, \mathrm{c})\end{array}$} \\
\hline Good (b) & 3.77 & 0.58 & \\
\hline Average (c) & 3.67 & 0.57 & \\
\hline $\operatorname{Bad}(\mathrm{d})$ & 3.81 & 0.58 & \\
\hline Too bad (e) & 0.00 & 0.00 & \\
\hline \multicolumn{4}{|l|}{ Academic performance } \\
\hline Very good & 4.50 & 0.58 & \multirow{5}{*}{$\mathrm{F}=1.366$} \\
\hline Good & 4.04 & 0.58 & \\
\hline Average & 3.98 & 0.68 & \\
\hline $\mathrm{Bad}$ & 4.03 & 0.62 & \\
\hline Too bad & 3.94 & 1.02 & \\
\hline \multicolumn{4}{|l|}{ Motivation of major select } \\
\hline On the aptitude beaten & 4.20 & 0.58 & \multirow{6}{*}{$\mathrm{F}=1.274$} \\
\hline The high employment rate & 4.12 & 0.70 & \\
\hline In consideration of the achievement & 3.89 & 0.66 & \\
\hline By invitation others & 3.87 & 0.68 & \\
\hline For service & 3.82 & 0.73 & \\
\hline Etc & 4.01 & 0.59 & \\
\hline \multicolumn{4}{|l|}{ Interpersonal relationships } \\
\hline Very good (a) & 4.37 & 0.66 & \multirow{5}{*}{$\begin{array}{c}\mathrm{F}=4.235^{*} \\
(\mathrm{a}>\mathrm{b}, \mathrm{c})\end{array}$} \\
\hline Good (b) & 4.03 & 0.63 & \\
\hline Average (c) & 3.77 & 0.58 & \\
\hline $\operatorname{Bad}(d)$ & 3.90 & 0.00 & \\
\hline Too bad (e) & 3.47 & 0.74 & \\
\hline \multicolumn{4}{|c|}{ Difficult interpersonal relationships in practicum } \\
\hline Prof. of clinical practicum (a) & 3.53 & 0.46 & \multirow{4}{*}{$\begin{array}{c}\mathrm{F}=4.989^{*} \\
(\mathrm{f}>\mathrm{a})\end{array}$} \\
\hline Practicum colleague (b) & 4.19 & 0.58 & \\
\hline Subjects (c) & 4.15 & 0.59 & \\
\hline Protector (d) & 4.48 & 0.49 & \\
\hline
\end{tabular}

Table 5. The results of $t$-test or one-way analysis of variance for teaching effectiveness of preceptor in according with the characterization of subject (continued)

\begin{tabular}{lccc}
\hline \multicolumn{1}{c}{ Characterization } & M & SD & \multicolumn{1}{c}{$t$ or F } \\
\hline Practicum audiologist (e) & 3.80 & 0.68 & \\
Administrative staff (f) & 5.00 & 0.00 & \\
Etc (g) & 4.09 & 0.63 & \\
Satisfaction of college life & & & \\
Very satisfaction (a) & 4.70 & 0.51 & \\
Satisfaction (b) & 4.10 & 0.51 & $\mathrm{~F}=11.249^{\dagger}$ \\
Average (c) & 3.78 & 0.61 & $(\mathrm{a}>\mathrm{b}, \mathrm{c}, \mathrm{d}, \mathrm{e} /$ \\
Dissatisfaction (d) & 3.66 & 0.84 & $\mathrm{~b}>\mathrm{c}, \mathrm{e})$ \\
Very dissatisfaction (e) & 2.95 & 0.00 & \\
Satisfaction of audiology major & & & \\
Very satisfaction (a) & 4.71 & 0.50 & \\
Satisfaction (b) & 4.01 & 0.53 & $\mathrm{~F}=18.409^{\dagger}$ \\
Average (c) & 3.67 & 0.58 & $(\mathrm{a}>\mathrm{b}, \mathrm{c}, \mathrm{d} /$ \\
Dissatisfaction (d) & 3.69 & 1.13 & $\mathrm{~b}>\mathrm{c})$ \\
Very dissatisfaction (e) & 0.00 & 0.00 & \\
Satisfaction of audiology practicum & & & \\
Very satisfaction (a) & 4.81 & 0.33 & \\
Satisfaction (b) & 4.14 & 0.47 & $\mathrm{~F}=44.644^{\dagger}$ \\
Average (c) & 3.51 & 0.50 & $(\mathrm{a}>\mathrm{b}, \mathrm{c}, \mathrm{d} /$ \\
Dissatisfaction (d) & 3.41 & 0.45 & $\mathrm{~b}>\mathrm{c}, \mathrm{d})$ \\
Very dissatisfaction (e) & 0.00 & 0.00 & \\
\hline * $p<0.01,{ }^{\dagger} p<0.001$. M: mean, SD: standard deviation & \\
& & &
\end{tabular}

의하게 교수 효율성이 높은 것으로 나타났다 $(p<0.01)$. 건강 상태가 매우 좋다고 생각하는 집단과 대인관계가 매우 좋다고 생각하는 집단이 그렇지 않은 집단보다 교수 효율성이 유의하 게 높은 것으로 나타났다 $(p<0.01, p<0.001)$. 실습 담당 지 도교수가 어려웠다고 생각한 집단이 실습 담당 관련 직원이 어 렵다고 생각하는 집단보다 실습 만족도가 유의하게 낮았다 $(p$ < 0.01). 대학생활과 청각 전공에 대해 매우 만족하는 집단이 다른 모든 집단보다 통계적으로 유의하게 교수 효율성이 높았다 $(p<0.001)$. 그러나 연령, 성별, 실습 시작 학기, 학업 성적, 전공 선택 동기에 따라서는 교수 효율성에 차이가 없었다.

\section{교수 효율성과 청각실습 만족도 하위 요인 간 상관}

교수 효율성의 하위 요인과 청각실습 만족도의 하위 요인 간 의 상관관계를 알아본 결과는 Table 6 과 같다. Table 6 에서 제시 한 바와 같이 교수 효율성과 관련된 하위 요인인 교수 능력, 인 성적 자질, 역할 모델, 상호관계, 학생 참여 유도와 청각실습 만 족도 관련된 하위 요인인 실습 내용, 실습 감독자, 실습 환경, 실 습 시간 및 평가, 실습 후 변화 간에 모두 유의한 양의 상관관계 를 보였다. 즉, 교수 효율성이 높을수록 실습 만족도도 높았다. 
Table 6. Pearson's correlation (coefficient) between each sub-items of teaching effectiveness and each sub-items of audiology clinical practicum

\begin{tabular}{|c|c|c|c|c|c|c|}
\hline $\begin{array}{l}\text { Auditory clinical } \\
\text { practicum satisfaction }\end{array}$ & $\begin{array}{l}\text { Teaching } \\
\text { ability }\end{array}$ & $\begin{array}{l}\text { Personality } \\
\text { qualities }\end{array}$ & Role models & Interrelationship & $\begin{array}{l}\text { Students } \\
\text { engage }\end{array}$ & $\begin{array}{l}\text { The total teaching } \\
\text { effectiveness of audiology } \\
\text { clinical practicum }\end{array}$ \\
\hline Practicum contents & $0.710^{*}$ & $0.581^{*}$ & $0.755^{*}$ & $0.695^{*}$ & $0.686^{*}$ & $0.731^{*}$ \\
\hline Practicum instructor & $0.787^{*}$ & $0.642^{*}$ & $0.772^{*}$ & $0.736^{*}$ & $0.783^{*}$ & $0.795^{*}$ \\
\hline Practicum environment & $0.691^{*}$ & $0.611^{*}$ & $0.677^{*}$ & $0.675^{*}$ & $0.649^{*}$ & $0.707^{*}$ \\
\hline Practicum time and evaluation & $0.776^{*}$ & $0.643^{*}$ & $0.668^{*}$ & $0.657^{*}$ & $0.746^{*}$ & $0.748^{*}$ \\
\hline The changing after practicum & $0.786^{*}$ & $0.623^{*}$ & $0.752^{*}$ & $0.723^{*}$ & $0.721^{*}$ & $0.770^{*}$ \\
\hline $\begin{array}{l}\text { The total satisfaction of audiology } \\
\text { clinical practicum }\end{array}$ & $0.855^{*}$ & $0.707^{*}$ & $0.824^{*}$ & $0.794^{*}$ & $0.815^{*}$ & $0.855^{*}$ \\
\hline
\end{tabular}
${ }^{*} p<0.001$

\section{DISCUSSIONS}

이 연구는 청각 전공 학생의 청각실습 교육의 질적 향상을 위하여 청각실습 만족도와 교수 효율성에 대해 알아보았다. 특 히 대상자 특성에 따른 청각실습 만족도 및 교수 효율성에 차이 가 있는가와, 청각실습 만족도와 교수 효율성 간 상관을 분석하 여 청각 전공 학생의 청각실습 지도에 효율적인 방향을 모색하 고자 하였다.

청각실습 만족도는 실습 후 변화, 실습 지도자, 실습 시간 및 평가, 실습 환경, 청각 실습 내용 순서로 만족도가 높은 것으로 나타났으며(전체 평균 3.91), 청각실습 내용 및 실습 환경을 제 외한 그 외 항목의 하위 구성 내용 간에는 통계적으로 차이가 나타나지 않았다. 청각 전공 학생들에게 만족도가 가장 낮았던 청각실습 내용은 실습 과정의 내용 구성, 수강한 이론의 실습 적용, 실제 청능사 업무 위주의 실습, 임상실습 시간에 무엇을 해야 할지 잘 모르거나 할 일이 없었던 경험, 대상자 문제 중심 의 실습으로 구성된 항목이다. 특히 임상실습 시간에 무엇을 해 야 할지 잘 모르거나 할 일이 없었던 경험, 대상자 문제 중심의 실습에 대한 만족도가 유의하게 나타났다. 언어치료 전공 학생 을 대상으로 실시한 연구에서 실습 만족도 평균은 3.89로 실습 감독자, 실습 후 변화, 실습 시간 및 평가, 실습 환경, 실습 내용 순으로 만족도가 높게 나타났다(Kim \& Shin, 2015). 또한 치과 기공과 학생들을 대상으로 실시한 연구에서도 실습 만족도 평 균이 3.25로 실습 내용과 관련된 설문 항목의 만족도가 가장 낮 은 것으로 나타났다(Sung et al., 2007). 본 연구에서도 만족도 가 가장 낮게 평가된 항목은 실습 내용으로 이 두 연구결과와 일치하게 나타났다. 청각실습 학생은 실습 과정을 통해서 자신 이 알고 있는 지식을 적용하고 배우면서 청능사의 역할을 습득 한다. 이 과정에서 실습 내용은 이미 이론 과목에서 다룬 내용 을 접목하는 교육 과정이므로 학생들의 관점에서 새로운 학습 내용으로 인식하지 않을 수 있다. 그러나 이러한 결과는 학생들 에게 실습 내용을 명확하게 하고, 학습한 이론을 실습에 적합하
게 적용하여 문제를 해결하는 문제기반 학습 적용이 필요함을 나타낸다(Kim \& Shin, 2015). 또한 청각실습 과정에서 무엇을 해 야 할지 잘 모르거나 할 일이 없었던 경험이 청각실습 만족도 저 하에 큰 영향을 미치는 것으로 나타났으므로 실습 시간을 보다 효 율적으로 활용할 수 있는 실습 내용이 필요할 것으로 생각된다.

청각실습 만족도가 두 번째로 낮았던 항목은 다양한 청각장 애 대상자에 대한 경험, 실습실의 크기와 실습생 수, 실습 장비 및 교구, 실습 및 임상 미팅 장소에 대한 항목으로 구성된 실습 환경으로 나타났는데, 특히 다양한 청각장애 대상자 경험에 대 한 만족도가 유의하게 낮았다. 이는 작업치료 임상실습에 대한 연구(Kim \& Kang, 2004)와 언어치료 임상실습에 대한 연구 (Kim \& Shin, 2015)에서 가장 필요한 실습 개선 항목 중 하나 가 실습 환경이라는 결과와 일치한다. Lee et al.(2017)의 연구에 따르면 각 대학별로 개설된 청각학 실습 과목의 수(1 3개의 실 습 교과목), 실습실 규모(1 8개의 실습실)에 상당히 차이가 있 는 것으로 나타났다. 대부분의 대학에서는 청능사자격검정원의 청능사 관리·운영 규정에 의거 총 240시간 이상-평가실습 $\geq$ 최 소 60 시간 이상, 보청기실습 최소 80 시간 이상, 재활실습 최소 60시간 이상) 실습을 운영하고 있으나, 본 연구에 따르면 청각 학 실습이 교내실습만으로 개설된 대학도 있는 반면, 교내실습 과 교외실습이 함께 개설된 대학도 있다. 교외실습의 경우에도 종합병원 및 개인병원, 개인 보청기 클리닉 등 실습 장소가 다 양하였다. 따라서 소속된 대학에 따라 실습 내용뿐 아니라 실 습생이 경험할 수 있는 청각장애 유형의 다양성, 교내·외 실습 시간 비율, 실습 장비(장비의 문제 또는 노후화 포함), 실습 장 소 등에서 크게 차이가 날 수 있으므로 청각 임상실습기관 선 정의 근거 마련 등을 포함하여 이에 대한 구체적인 개선 방안 이 논의되어야 할 것이다. 또한 향후 청각학 전공 학생들의 실 습 만족도를 향상시키기 위한 정기적인 만족도 및 요구도 조사 와 이에 대한 환류 시스템의 도입도 필요하다.

청각실습의 교수 효율성은 역할 모델, 상호관계, 인성적 자 질, 학생 참여 유도, 교수 능력 순서로 효율성이 높게 나타났으 
나(전체 평균 4.04), 각 항목의 하위 구성 내용 간에는 통계적으 로 차이가 나타나지 않았다. 교수 효율성 평가 항목 중 효율성 이 가장 낮았던 하위 항목은 실습에 대한 학습 동기 부여, 더 많은 것을 배울 기회와 새로운 기술을 습득할 수 있도록 도움 제공, 실습 목표 및 지도 내용의 명확성, 수업 내용과 실무와의 연결, 전문직으로서의 책임감, 성적 평가 기준의 타당성, 임상 과 관련된 적절한 질문과 답변 제공, 자유로운 토의 등에 관한 세부 평가 항목으로 구성된 교수 능력이었다. 다음으로 교수 효 율성이 낮았던 하위 항목은 새로운 기술 및 창의적인 요소를 활용할 수 있도록 도움 제공, 진단 및 치료 절차를 스스로 익힐 수 있도록 안내, 실습일지와 보고서를 규정에 맞게 작성하도록 안내, 평가 장비 및 중재 도구를 스스로 검점하고 준비할 수 있 도록 도움 제공 등에 관한 세부 평가 항목으로 구성된 학생 참 여 유도였다. 치과기공과 실습생을 대상으로 한 연구(Sung et al., 2007)에서 교수 효율성은 평균 3.35로 실습생에 대한 격려 와 지지, 학생을 위한 유용성 측면에서 개선이 필요하다고 제안 하였다. 또한 본 연구에서 이용한 교수 효율성 평가 항목과 거 의 유사하게 구성된 언어치료 전공 학생을 대상으로 한 선행연 구(Kim \& Shin, 2015)에서 교수 효율성은 평균 4.19로 교수 능 력, 상호관계 평가 항목에서 비교적 낮은 점수를 나타냈다. 언 어치료 임상실습은 주로 교내실습으로 이루어지며, 거의 대부 분 전임교원과 임상실습 전문교수가 지도하고 있는 반면, 청각 학실습의 경우 교내 또는 교내·외 실습으로 대학마다 다르며, 실습 담당 교원의 자격 및 실습 과목을 담당하는 전임교원의 비중이 대학별로 상당히 차이가 났다(Lee et al., 2017). 교수 효 율성에 대한 선행연구(Shin \& Kim, 1999)에 따르면 교과목 이 론 담당교수가 실습을 담당하는 경우 이론과 실무가 연계되어 교수 효율성이 향상된다고 하였는데, 청각학실습의 교수 효율 성이 언어치료 분야에 비해 유의하게 낮은 주된 원인은 실습 과 목을 담당하는 청각학 전공 전임교원의 비율이 낮기 때문으로 추측된다(Lee et al., 2017) (Appendix). 따라서 Lee et al.(2017) 이 제안한 것처럼, 전임교원이 실습 교과목을 담당하는 것이 가 장 적절하나 비전임교원이 실습 교과목을 담당할 경우 실습 담 당 비전임교원의 자격 요건을 청각학 전공자인 동시에 전문청능 사를 획득하여 유지하고 있는 전문가로 한정하여 실습 교육의 질을 유지해야 할 필요성이 있다. 또한 Kim \& Shin(2015)이 제 안한 것처럼 본 연구결과에서도 실습 담당 교원의 교수 능력과 학생 참여 유도를 포함한 교수 효율성을 향상시킬 수 있는 체 계적인 프로그램 마련이 필요할 것으로 생각된다.

대상자 특성에 따른 청각실습 만족도는 청각실습 기간, 건강 상태, 대인관계 및 청각실습에서 어려웠던 대인관계, 대학생활 및 청각 전공 만족도에서 통계적으로 유의한 차이가 나타났 다. 청각실습 기간에서는 2 학기 동안 실습을 경험한 학생에 비
해 4학기 동안 실습을 경험한 학생의 실습 만족도가 더 높았는 데 $(p<0.01)$, 이는 수강 교과목 체계와 관련된 것으로 청각학 전공에서의 실습은 청능 평가, 보청기·인공와우 적합, 청능재 활 영역으로 구분되어 있고, 관련 영역마다 필요한 이론적 지식 이 매우 상이하다. 따라서 영역별 이론 교과목을 이수한 후 가 능한 빨리 실습을 진행하고 실무를 경험할 수 있는 시간을 많 이 투자할수록 임상 실무 역량이 높아지기 때문에 실습 만족 도가 높은 것으로 생각된다. 이에 반해 언어치료 전공에서의 임 상실습은 학년과 임상실습 시작 학기에 따라 만족도가 유의하 게 차이 났는데, 이는 언어치료 관련 영역을 모두 배우지 않고 실습을 시작한 것 때문이라고 제안하였다(Kim \& Shin, 2015). 건강 상태 및 대인관계 항목에서는 건강 상태가 매우 좋다고 생각하는 집단과 대인관계가 매우 좋다고 생각하는 집단이 그 렇지 않은 집단보다 실습 만족도가 유의하게 높은 것으로 나타 났는데 $(p<0.01, p<0.001)$, 이러한 본 연구결과는 건강 상태, 대인관계가 언어치료 전공 학생의 임상실습 만족도와 통계적으 로 유의한 차이가 나타나지 않은 선행연구(Kim \& Shin, 2015) 와는 차이가 있다. 청각실습에서 어려웠던 대인관계 항목에서 는 기타(41.9\%), 대상자(16.1\%), 실습 지도교수(14.5\%), 실습 동 료(10.5\%), 실습 담당 청능사(9.7\%), 보호자 $(4.0 \%)$, 행정직원 (3.2\%) 순으로 나타나, 언어치료 임상실습에서 보호자, 실습 동 료, 임상실습 조교, 임상 지도교수, 언어치료 대상자, 기타 등의 순으로 대인관계가 어렵다고 나타난 선행연구(Kim \& Shin, 2015)와는 차이가 나타났다. 이와 같이 상기 두 학문 분야에서 어려웠던 대인관계의 차이는 언어치료 임상실습은 주로 교내실 습으로 이루어지고 그 과정에서 보호자와의 상담이 필수적인 데 반해, 청각 임상실습은 교내 또는 교내·외 실습으로 대학마 다 차이가 있으며, 보호자와의 상담은 큰 비중을 차지하지 않 기 때문으로 학문 분야에 따른 임상실습 체계의 차이로 인한 것으로 생각된다. 또한 실습 지도교수와의 소통이 어려웠던 집 단의 실습 만족도가 가장 낮았으므로 실습 지도교수와의 소통 을 강화하는 체계적인 지도 방법과 대상자를 대면하는 교육이 마련되어야 할 것으로 생각된다.

대부분의 선행연구(Kim \& Jung, 2006; Kim \& Shin, 2015; Sung et al., 2007)에서와 같이 본 연구에서도 대학생활 및 청 각 전공 만족도가 높을수록 청각실습 만족도가 높은 것으로 나타났다. $\operatorname{Kim} \& \operatorname{Shin}(2015)$ 은 대학생활과 전공 만족도가 높 을수록 교육 과정에서 적극적으로 참여할 가능성이 높고, 이는 실습에 대한 동기로 이어져 실습 만족도를 향상시킬 수 있다고 제안하였으므로 대학생활과 전공 만족도를 향상시킬 수 있는 방안에 대한 연구가 지속적으로 필요할 것으로 생각된다.

대상자 특성에 따른 교수 효율성은 청각실습 만족도와 동일 하게 청각실습 기간, 건강 상태, 대인관계 및 청각실습에서 어 
려웠던 대인관계, 대학생활 및 청각 전공 만족도에서 통계적으 로 유의한 차이가 나타났다. 청각실습 기간에서는 2학기 동안 실습을 경험한 학생에 비해 4학기 동안 실습을 경험한 학생의 교수 효율성이 더 높았으며 $(p<0.01)$, 건강 상태 및 대인관계 항 목에서도 실습 만족도와 동일하게 건강 상태가 매우 좋다고 생 각하는 집단과 대인관계가 매우 좋다고 생각하는 집단이 그렇 지 않은 집단보다 교수 효율성이 유의하게 높은 것으로 나타났 는데 $(p<0.01)$, 이러한 결과는 청각실습 만족도와 동일하였다. 이러한 본 연구결과는 실습 기간, 건강 상태, 대인관계가 교수 효율성과 통계적으로 유의하게 나타나지 않은 선행연구(Kim \& Shin, 2015; Oh, 2013)와는 차이가 있다. 그러나 본 연구의 청각실습 만족도 결과는 선행연구(Kim \& Shin, 2015; Oh, 2013; Yoon \& Kim, 2013)와 일치하게 대학생활 및 전공 만족 도가 높을수록 청각실습에서의 교수 효율성도 높은 것으로 나 타났다. 따라서 청각실습 지도교수는 청각실습을 통해 청각 전 공 학생들의 전문적인 실무역량을 강화시켜야 할 뿐 아니라 대 학생활 및 전공에 대한 만족도를 높여 학교 및 학과 생활에 적 응할 수 있도록 도움을 주어야 할 것으로 생각된다.

교수 효율성과 청각실습 만족도 하위 요인 간 상관에서는 모 든 항목이 통계적으로 유의한 양의 상관관계를 나타내었다. 청 각실습 만족도의 모든 하위 요인은 교수 효율성과 0.70 이상의 상관관계를 보였는데, 특히 실습 지도자 및 실습 후 변화와 관 련된 요인은 각각 $0.79,0.77$ 이상의 상관관계로 나타났다. 교수 효율성의 모든 하위 요인 또한 실습 만족도와 0.70 이상의 상관 관계를 보였으며, 특히 교수 능력, 역할 모델, 학생 참여 유도와 관련된 요인은 각각 $0.85,0.82,0.81$ 이상의 상관관계로 나타났 다. 다수의 선행연구(Kim \& Jung, 2006; Kim \& Shin, 2015; Oh, 2013; Sung et al., 2007)에서와 같이 본 연구에서도 교수 효율성은 실습 만족도에 상당한 영향을 미치는 것으로 나타났 다. 그러나 본 연구에서도 $\operatorname{Kim} \& \operatorname{Shin}(2015)$ 의 연구에서와 같 이 교수 효율성이 청각실습 만족도에 비해 높게 나타나 교수 효 율성이 실습 만족도로 그대로 반영되지 않았다고 생각된다. 이 러한 이유는 대상자 특성 중 일부 요인이 작용한 것으로 생각 된다. 따라서 교수 효율성의 향상뿐 아니라 청각실습 만족도가 낮았던 실습 환경, 실습 시간 및 평가, 실습 내용 등과 관련된 다양한 요인을 파악하고 이를 개선하여 최상의 청각실습을 경 험할 수 있도록 노력해야 할 것이다.

본 연구결과를 종합해 보면 청각학 분야에서 교수 효율성과 청각실습 만족도는 임상실습이 필수적인 보건계열학과 등과 비 슷하거나 높은 수준으로 상관관계가 매우 높은 편이었으며, 교 수 효율성이 청각실습 만족도에 상당한 영향을 미치는 것으로 나타났다. 따라서 청각학 전공 대학 및 한국청각학전공교수협의 회에서는 청각 전공 학생들의 청각실습 만족도를 향상시킬 수
있는 구체적인 실습 지도 계획 및 임상실무 지침을 개발하고, 이 를 환류하는 체계적인 시스템의 도입을 적극 고려해야 할 것이 다. 본 연구를 통해 청각실습 교육과 청각 전공 학생들의 임상 실 무 능력을 질적으로 향상시킬 수 있는 계기를 마련하고 전문적인 임상 실무 능력을 갖춘 청능사를 양성할 수 있기를 기대한다.

중심 단어 : 청각학·만족도·교수 효율성·임상실습.

\section{Ethical Statement}

The study was approved by the Institutional Review Board of the Catholic University of Pusan (CUPIRB-2019-207).

\section{Acknowledgments}

The author thank to the participants. Also, author thank to Professor In-Ki Jin, Soo-Jin Cho, Mee-Hye Park for their assistance in collecting the data. Finally, author would like to thank Professor Myung-Sun Shin for her assistance in drafting of the manuscript and analyzing the data.

\section{Declaration of Conflicting Interests}

There are no conflict of interests.

\section{Funding}

N/A

\section{ORCID iD}

Jin-Dong Kim https://orcid.org/0000-0001-9421-9481

\section{REFERENCES}

American Academy of Audiology. (2004, January 30). Scope of Practice. Audiology. Retrieved from https://www.audiology.org/publications-resources/document-library/scope-practice.

Han, J. Y. \& Park, H. S. (2011). Effects of teaching effectiveness and clinical learning environment on clinical practice competency in nursing students. Journal of Korean Academy of Fundamentals of Nursing, 18(3), 365-372.

Kim, J. K. \& Kang, D. H. (2004). The survey on the perception of occupational therapy faculty on the clinical fieldwork. The Journal of Korean Society of Occupational Therapy, 12(2), 91-103.

Kim, J. S. \& Jung, Y. H. (2006). A study on correlation of teaching efficiency and satisfaction of clinical training in Daegu. The Journal of Korean Academy of Dental Technology, 28(1), 121-142.

Kim, K. E. \& Lee, B. Y. (2014). The relationship between satisfaction with clinical practice and clinical performance ability for nursing students. The Journal of the Korea Contents Association, 14(10), 885-896.

Kim, S. Y. \& Shin, M. S. (2015). A study of the satisfaction and teaching efficiency of clinical practice of students majoring in speech-language pathology. Journal of Speech Language and Hearing Research, 24(4), 17-31.

Lee, J. H., Lee, J. Y., Cho, S. J., Park, S. I., Kim, J. D., Park, M. H., et al. (2017). A survey of educational environment for the accreditation of audiology and hearing sciences education. Audiology and Speech Research, 13(3), 193-208.

Oh, H. S. (2013). Study on the teaching efficiency and satisfaction levels of clinical practice instructors during clinical practice training for some dental hygienists and students. Journal of Korean Society of Dental Hygiene, 13(5), 777-786

Shin, K. R. \& Kim, M. A. (1999). A study of teaching effectiveness on clinical nursing education. Journal of Research in Curriculum Instruction, 3(1), 289-317

Sung, H. K., Lee, K. S., \& Hwang, J. S. (2007). A study on correlation of teaching efficiency and satisfaction of clinical practice of dental tech- 
nology students (in Seoul and Kyung-ki). The Journal of Korean Academy of Dental Technology, 29(1), 59-72.

Yoon, J. H. \& Kim, J. W. (2013). A survey on the satisfaction and perception of the clinical practicum of students majoring in speech language pathology. Journal of Speech-Language and Hearing Disorders, 22(4),
251-270.

Yu, Y. H. (1997). Research on teaching effectiveness of clinical nursing education of junior nursing colleges (Unpublished master's thesis). Ewha Womans University, Seoul. 


\section{APPENDIX}

\section{청각실습 만족도 및 교수 효율성 설문지}

1. 다음은 일반적 특성에 관한 내용입니다. 해당되는 항목에 $\checkmark$ 표, 혹은 직접 기입해 주십시오.

$\begin{array}{ll}\text { 1) 성별 (1) 남 } & \text { (2) 여 }\end{array}$
2) 연령
(1) $21 \sim 24$ 세
(2) $25 \sim 30$ 세
(3) $31 \sim 34$ 세
(4) $35 \sim 40$ 세
(5) 41 세 이상

3) 청각실습 기간
(1) 1 학기 동안
(2) 2학기 동안
(3) 3학기 동안
(4) 4학기 동안
(5) 5 학기 이상

4) 청각실습 시작 학기
(1) 2학년 2학기
(2) 3학년 1학기
(3) 3학년 2학기
(4) 4학년 1학기
(5) 4학년 2학기

5) 청각실습 장소(중복 체크 가능)

(1) 교내 청각실습실 (2) 종합병원 청력검사실 (3) 개인병원 청력검사실 (4) 개인 보청기 클리닉

6) 주 실습 지도자(중복 체크 가능)
(1) 전임교수
(2) 실습 전담교수
(3) 시간강사
(4) 현장 청능사
(5) 기타

7) 건강 상태

(1) 매우 좋다 (2) 좋다 (3) 보통 (4) 좋지 않다 (5) 매우 좋지 않다

8) 학업 성적
(1) 매우 좋다
(2) 좋다 (3) 보통
(4) 좋지 않다
(5) 매우 좋지 않다

9) 전공 선택 동기

(1) 적성에 맞아서 (2) 취업률이 높아서 (3) 성적을 고려해서 (4) 타인이 권유해서 (5) 봉사직을 갖기 위해서 (6) 기타 ( )

10) 대인관계
(1) 매우 원만함
(2) 원만함
(3) 보통
(4) 원만하지 못함
(5) 매우 원만하지 못함

11) 청각실습에서 어려웠던 대인관계

(1) 실습 지도교수 (2) 실습 동료 (3) 청각 대상자 (4) 대상자의 보호자 (5) 실습 담당 청능사 (6) 행정 담당 직원 (7) 기타

12) 대학생활 만족도
(1) 매우 만족
(2) 만족
(3) 보통
(4) 불만족
(5) 매우 불만족

13) 청각 전공 만족도
(1) 매우 만족
(2) 만족 (3) 보통
(4) 불만족 (5) 매우 불만족

14) 청각실습 만족도
(1) 매우 만족
(2) 만족
(3) 보통
(4) 불만족
(5) 매우 불만족

15) 청각실습 교육의 문제점이나 개선점에 대한 의견이 있다면 기술해 주시기 바랍니다. 
2. 다음은 청각실습 만족도를 알아보기 위한 문항입니다. 자세히 읽고 해당되는 곳에 $\checkmark$ 표 해주세요.

\begin{tabular}{|c|c|c|c|c|c|c|}
\hline \multirow[t]{2}{*}{ 특 성 } & \multirow[t]{2}{*}{ 문 항 } & $\begin{array}{c}\text { 매우 } \\
\text { 그렇다 }\end{array}$ & 그렇다 & $\begin{array}{l}\text { 보통 } \\
\text { 이다 }\end{array}$ & $\begin{array}{c}\text { 그렇지 } \\
\text { 않다 }\end{array}$ & $\begin{array}{c}\text { 매우 } \\
\text { 그렇지 } \\
\text { 않다 } \\
\end{array}$ \\
\hline & & 5 & 4 & 3 & 2 & 1 \\
\hline \multirow{5}{*}{$\begin{array}{l}\text { 실습 } \\
\text { 내용 }\end{array}$} & 실습 과정은 적합한 내용으로 구성되었다 & & & & & \\
\hline & 수강한 이론이 임상실습에 적절히 적용되었다 & & & & & \\
\hline & 단순 학습이 아니라 실제 청능사 업무 위주의 실습을 하였다 & & & & & \\
\hline & 임상실습 시간에 무엇을 해야 할지 잘 모르거나 할 일이 없었던 적이 있다 & & & & & \\
\hline & 단순 기능적 실습보다는 대상자의 문제 중심 임상실습을 수행하였다 & & & & & \\
\hline \multirow{5}{*}{$\begin{array}{c}\text { 실습 } \\
\text { 지도자 }\end{array}$} & 지도자는 실습 내용을 흥미로운 방향으로 지도하였다 & & & & & \\
\hline & 지도자는 학생에게 열정을 갖고 지도하였다 & & & & & \\
\hline & 지도자는 이론을 실제 임상에 적용하도록 지도하였다 & & & & & \\
\hline & 지도자는 보고서 작성에 대한 피드백을 적절하게 하였다 & & & & & \\
\hline & 지도자는 대상자에 따른 평가 및 재활 방법에 대한 피드백을 적절하게 하였다 & & & & & \\
\hline \multirow{5}{*}{$\begin{array}{l}\text { 실습 } \\
\text { 환경 }\end{array}$} & 다양한 청각장애 대상을 경험할 수 있었다 & & & & & \\
\hline & 실습기관의 공간과 실습생 수가 적절하였다 & & & & & \\
\hline & 임상실습 장비 및 교구가 다양하였다 & & & & & \\
\hline & 임상실습 장소가 청결하고 안정적이었다 & & & & & \\
\hline & 실습기관이 환자를 관찰하고 토의하기에 적절하였다 & & & & & \\
\hline \multirow{5}{*}{$\begin{array}{c}\text { 실습 } \\
\text { 시간 } \\
\text { 및 평가 }\end{array}$} & 청각실습 기간이 적절하였다 & & & & & \\
\hline & 청각실습 시간이 적절하였다 & & & & & \\
\hline & 청각실습 시작 학기가 적절하였다 & & & & & \\
\hline & 청각실습 평가 기준이 적절하였다 & & & & & \\
\hline & 청각실습 평가 방법이 적절하였다 & & & & & \\
\hline \multirow{5}{*}{$\begin{array}{c}\text { 실습 } \\
\text { 후 변화 }\end{array}$} & 청각실습의 중요성과 필요성을 느겼다 & & & & & \\
\hline & 청각실습을 통하여 청능사로서의 보람과 자부심을 느겼다 & & & & & \\
\hline & 청각장애 평가와 중재 기술이 향상되었다 & & & & & \\
\hline & 환자를 맞이하는 기술과 검사 결과를 해석하고 설명하는 기술이 향상되었다 & & & & & \\
\hline & 청각실습이 졸업 후 청능사의 직무를 수행하는 데 많은 도움이 될 것이다 & & & & & \\
\hline
\end{tabular}


3. 다음은 청각실습 교육의 교수 효율성를 알아보기 위한 문항입니다. 자세히 읽고 해당되는 곳에 $\checkmark$ 표 해주세요.

\begin{tabular}{|c|c|c|c|c|c|c|}
\hline 특 성 & 문 & \begin{tabular}{c|} 
매우 \\
그렇다
\end{tabular} & 그렇다 & $\begin{array}{l}\text { 보통 } \\
\text { 이다 }\end{array}$ & $\begin{array}{l}\text { 그렇지 } \\
\text { 않다 }\end{array}$ & $\begin{array}{c}\text { 매우 } \\
\text { 그렇지 } \\
\text { 않다 }\end{array}$ \\
\hline & & 5 & 4 & 3 & 2 & 1 \\
\hline \multirow{13}{*}{$\begin{array}{l}\text { 교수 } \\
\text { 능력 }\end{array}$} & 청각실습 지도자는 학생들에게 청능 실습에 대한 학습동기를 부여한다 & & & & & \\
\hline & 청각실습 지도자는 실습 시간에 더 많은 것을 배울 기회를 제공한다 & & & & & \\
\hline & 청각실습 지도자는 새로운 기술을 습득하는 데 도움을 준다 & & & & & \\
\hline & 청각실습 지도자는 실습할 때 실습 목표를 분명하게 설명한다 & & & & & \\
\hline & 청각실습 지도자는 수업 시간에 배운 내용을 실무와 연결시켜 준다 & & & & & \\
\hline & 청각실습 지도자는 전문직으로서의 책임감을 심어준다 & & & & & \\
\hline & 청각실습 지도자는 성적 평가에 타당한 기준을 사용한다 & & & & & \\
\hline & 청각실습 지도자는 다양한 사례를 지도해 준다 & & & & & \\
\hline & 청각실습 지도자의 지도 내용은 명확하다 & & & & & \\
\hline & 청각실습 지도자는 실습 시 요구되는 상황을 명확히 제시해 준다 & & & & & \\
\hline & 청각실습 지도자는 교육 내용을 알기 쉽게 지도해 준다 & & & & & \\
\hline & 청각실습 지도자는 임상과 관련된 적절한 질문과 답변을 제공한다 & & & & & \\
\hline & 청각실습 지도자는 임상실습 시간에 자유롭게 토의가 이루어지도록 한다 & & & & & \\
\hline \multirow{6}{*}{$\begin{array}{l}\text { 인성적 } \\
\text { 자질 }\end{array}$} & 청각실습 지도자는 다정하고 인내심을 가지고 있다 & & & & & \\
\hline & 청각실습 지도자는 학생을 진솔하게 대한다 & & & & & \\
\hline & 청각실습 지도자는 학생에게 많은 관심을 가진다 & & & & & \\
\hline & $\begin{array}{l}\text { 청각실습 지도자는 언제나 편하게 도움을 청하고 질문할 수 있는 분위기를 } \\
\text { 만들어 준다 }\end{array}$ & & & & & \\
\hline & 청각실습 지도자는 학생을 존중해 준다 & & & & & \\
\hline & 청각실습 지도자는 열정을 갖고 실습을 진행한다 & & & & & \\
\hline \multirow{6}{*}{$\begin{array}{l}\text { 역할 } \\
\text { 모델 }\end{array}$} & 청각실습 지도자는 실습에 문제가 생겼을 때 원만하게 대처해 준다 & & & & & \\
\hline & 청각실습 지도자는 상황에 따라 적절한 융통성을 보여준다 & & & & & \\
\hline & 청각실습 지도자는 청각전문가로서 충분한 자질을 겸비하고 있다 & & & & & \\
\hline & 청각실습 지도자는 청능재활에 대한 많은 관심과 흥미를 보여준다 & & & & & \\
\hline & 청각실습 지도자는 실습 과정에 대하여 조언을 해 준다 & & & & & \\
\hline & 청각실습 지도자는 전반적으로 충분한 능력을 가지고 있다 & & & & & \\
\hline \multirow{5}{*}{$\begin{array}{l}\text { 상호 } \\
\text { 관계 }\end{array}$} & 청각실습 지도자는 실습 시간 외에도 적극적으로 학생을 지도해 준다 & & & & & \\
\hline & 청각실습 지도자는 학생의 개인적인 비밀을 철저히 지켜준다 & & & & & \\
\hline & 청각실습 지도자는 학생의 실수를 적절하게 수정해 준다 & & & & & \\
\hline & 청각실습 지도자는 학생과 좋은 관계를 유지한다 & & & & & \\
\hline & 청각실습 지도자는 학생이 청능사 직무에 대하여 흥미를 느낄 수 있게 해준다 & & & & & \\
\hline \multirow{5}{*}{$\begin{array}{l}\text { 학생 } \\
\text { 참여 } \\
\text { 유도 }\end{array}$} & 청각실습 지도자는 실습에서 새로운 것을 활용할 수 있도록 도와준다 & & & & & \\
\hline & 청각실습 지도자는 학생에게 창의적인 요소들을 활용할 수 있도록 도와준다 & & & & & \\
\hline & 청각실습 지도자는 진단 및 치료 절차를 스스로 익힐 수 있도록 안내한다 & & & & & \\
\hline & 청각실습 지도자는 실습일지와 보고서를 규정에 맞게 작성하도록 한다 & & & & & \\
\hline & $\begin{array}{l}\text { 청각실습 지도자는 평가 장비 및 중재 도구를 스스로 점검하고 준비하도록 } \\
\text { 도와준다 }\end{array}$ & & & & & \\
\hline
\end{tabular}

